\title{
Н. Б. Антипова
}

\section{Дидактические функции визуальной опоры в процессе обучения русскому языку как иностранному на начальном этапе}

В статье раскрыты понятия визуализащия и визуальная опора, рассмотрены типьы визуальных опор, применяемых автором на начальном этапе обучения русскому языку как иностранному, описаны дидактические функции визуальной опоры как многофункционального средства наглядности, которое способствует образованию правильных представлений об изучаемых явлениях языка и культуры, помогает восприятию и порождению речи. Автор обосновывает необходимость использования визуальных опор при обучении говорению на начальном этапе, описывает собственный опыт работы с визуальными опорами в процессе обучения русскому языку полилингвальной аудитории в условиях зарубежного вуза.

Ключевые слова: наглядность, визуализация, визуальная опора, визуальная среда обучения, типы визуальных опор, функции визуальной опоры, полилингвальная аудитория, обучение русскому языку как иностранному, иностранные студенты.

Как известно, использование средств наглядности является важнейшим ресурсом при обучении русскому языку как иностранному. Идея наглядности в обучении впервые была выдвинута и описана в трудах Я. А. Коменского, усматривавшего в наглядности средства для развития наблюдательности, мышления и речи. Принцип наглядности ученый противопоставлял словесному, пассивному обучению [12, с. 329-330].

Последователями Я. А. Коменского были Ж.-Ж. Руссо, И. Г. Песталоцци, Ф. А. Дистервег, К. Д. Ушинский, Л. Н. Толстой и другие авторы, в работах которых утверждалась идея использования в обучении средств предметной наглядности: картин, изображений, рисунков, таблиц, моделей. И. Г. Песталоцци называет наглядность необходимой основой всякого обучения [15, с. 183]. Ф. А. Дистервег отмечает, что истинные, живые и убедительные представления о важных вещах возникают исключительно только благодаря наглядному, развивающему обучению [8, с. 301]. К. Д. Ушинский понимает под наглядным обучением «такое ученье, которое строится не на отвлеченных представлениях и словах, а на конкретных образах, непосредственно воспринятых ребенком» [19, с. 444].

В современной дидактике принцип наглядности остается одним из ведущих в системах проблемного (А. М. Матюшкин, М. И. Махмутов, И. Я. Лернер и др.) и развивающего обучения (В. В. Давыдов, Д. Б. Эльконин и др.).

Значительный вклад в исследование возможностей использования наглядно-изобразительных средств в процессе обучения русскому языку в школе и вузе внесли Е. А. Вострикова [4], Г. Г. Городилова [6], Л. М. Зельманова [11]. Идеи данных ученых-исследователей представляются чрезвычайно интересными и перспективными применительно к проблеме обучения русскому языку как иностранному полилингвальной аудитории.

Анализ литературы по проблемам наглядности и визуализации позволяет высказать предположение, что термин визуализация пришел в методику под влиянием западной традиции. Введение нового термина обусловлено тем, что в методике появилась необходимость отличать учебную наглядность в традиционном классическом понимании (предметы, модели, картины, изображения и т.д.) от наглядности, создаваемой с помощью новых информационно-технических средств обучения.

В настоящее время визуализации придается большое значение, что обусловлено «изменениями технологий преподавания, в том числе технологий предъявления учебной

(C) Антипова Н. Б., 2019 
Электронный научный журнал (Online). ISSN 2303-9922. http://www.vestospu.ru

информации» [9, с. 7; 10, с. 44]. Как известно, понятие «визуализация» происходит от латинского слова visualis - зрительный, видимый, наглядный, визуальный.

«Новый словарь методических терминов и понятий» определяет визуализацию как «представление физического явления или процесса в форме, удобной для зрительного восприятия» [3, с. 38].

Э. Н. Абдулаев под визуализацией понимает «способ получения и обобщения знаний на основе зрительного образа понятия, события, процесса, явления, факта и т.п., основанный на ассоциативном мышлении и системном структурировании информации в наглядной форме» [2, с. 7-8].

А. Г. Рапуто определяет визуализацию как «всякий способ обеспечения наблюдаемости реальности, а под результатом визуализации или визуальной моделью — любую зрительно воспринимаемую конструкцию, имитирующую сущность объекта познания» $[16$, c. 138$]$.

«Процесс визуализации, по А. А. Вербицкому, - это свертывание мыслительных содержаний в наглядный образ; будучи воспринятым, образ может быть развернут и служить опорой адекватных мыслительных и практических действий» [10, с. 45].

Наиболее полное, на наш взгляд, определение визуализации дает профессор Т. Т. Сидельникова в статье, посвященной исследованию потенциала и барьеров применения визуализации. Автор говорит о визуализации как «о знаковом (символьном) представлении содержания, функций, структуры, этапов (стадий) какого-либо процесса, явления, осуществляемом через схематизацию (схемоязык, интеллект-карты, структурно-логические схемы) и ассоциативно-иллюстративный ряд» [18, с. 281, 285]. А также как «о педагогическом методе, основанном на принципе наглядности, в рамках которого через схематизацию и ассоциативно-иллюстративный ряд осуществляется знаковое (символьное) представление содержания, функций, структуры, этапов (стадий) какого-либо процесса или явления» [там же].

Таким образом, применительно к учебному процессу под визуализацией мы будем понимать процесс реализации принципа наглядности путем использования визуальных опор. Цель визуализации - сделать доступными зрительному восприятию существенные особенности объекта для облегчения понимания, усвоения и использования в речи.

Под визуальной опорой мы понимаем такое средство наглядности, которое позволяет преподавателю проиллюстрировать на уроке изучаемый языковой и социокультурный материал на печатном или электронном носителе. Такая опора способствует образованию правильных представлений об изучаемых явлениях языка и культуры, помогает восприятию и порождению речи, позволяет предъявить информацию в удобной для восприятия форме, создавая тем самым визуальную среду обучения.

При работе с полилингвальной группой вне языковой среды, где перед преподавателем одновременно оказываются представители западных и восточных культур и где на говорение отводится 1 час в неделю, без визуализации не обойтись. В нашем случае в Страсбургском университете аудитория первого года обучения представлена студентами из более чем 20 стран (Франции, Сербии, Болгарии, Грузии, Бельгии, Люксембурга, Израиля, Турции и др.). Как показал опрос, из них 70\% франкофоны и $30 \%$ инофоны.

В условиях работы с полилингвальной аудиторией принцип наглядности, «золотое правило дидактики» Я. А. Коменского, получает новое рождение через визуализацию, через использование визуальных опор (презентаций, фотоколлажей, стоп-кадров и др.), где учебная информация представляется в наглядном и доступном для восприятия и усвоения виде.

Педагоги и методисты рекомендуют широко использовать средства наглядности для создания речевых ситуаций $[5 ; 7 ; 14 ; 17 ; 20 ; 22 ; 23]$. Как отмечает А. Н. Щукин, использо- 
Электронный научный журнал (Online). ISSN 2303-9922. http://www.vestospu.ru

вание визуальных опор «позволяет восполнить отсутствие языковой среды» [20, с. 575]. Можно добавить, что в полилингвальной аудитории визуальные опоры позволяют также проиллюстрировать родные реалии учащихся. М. В. Ляховицкий писал, что «основное назначение наглядности заключается в оптимизации процесса усвоения учебной информации, создании более или менее ярко выраженной иллюзии приобщения к естественной языковой среде, к условиям, в которых функционирует иноязычная речь» [13, с. 22].

Урок русского языка как иностранного вне языковой среды невозможно представить без ярких картин, фотографий, рисунков, коллажей, видеорядов, иллюстрирующих российские реалии и позволяющих говорить о них.

В. Д. Янченко, говоря о наглядности как действенном и эффективном средстве обучения русскому языку китайских студентов, подчеркивает, что использование наглядности «представляется логичным и научно обоснованным, поскольку опора на принцип наглядности способствует развитию коммуникативной компетенции студентов, обогащает их знаниями страноведческого характера», «позволяет успешно преодолеть объективные и субъективные трудности» [21, с. 2174, 2177].

В плане развития навыков говорения визуальная наглядность, отмечает И. Э. Абдрахманова, может быть использована «для создания речевого образца, смысловой опоры, ситуации общения, стимулирующей высказывание» [1, с. 211].

Опыт работы показывает, что средства наглядности для полилингвальной аудитории должны быть адаптированы с учетом контингента и соответствовать следующим критериям:

- мотивировать учащегося к общению в рамках полилога культур;

- помогать понять реалии страны изучаемого языка;

- помогать рассказать о своей культуре и родных реалиях.

Как средство обучения визуальная опора многофункциональна.

Можно выделить следующие дидактические функции визуальной опоры при обучении говорению полилингвальной группы:

1. Информативная - визуальная опора является наглядным источником информации об изучаемом языке и культуре, а также о других культурах, представителями которых являются сами студенты.

2. Мотивирующая - использование визуальной опоры мотивирует к говорению и общению на изучаемом языке; побуждает анализировать и сравнивать различные языки и культуры.

3. Обучающая - использование визуальной опоры позволяет расширить языковые знания студентов в области фонетики и грамматики, обогатить словарь и запас грамматических моделей высказывания.

4. Развивающая - работа с визуальной опорой позволяет развивать языковую, коммуникативную, культуроведческую компетенции, моделировать различные ситуации для говорения, развивать и совершенствовать языковые умения, навыки говорения; расширить кругозор, вызвать интерес к иным культурам; работа с визуальной опорой позволяет развивать творческие способности, внимание и память.

5. Воспитательная - работа с визуальной опорой способствует воспитанию уважительного отношения, принятия и толерантности по отношению друг к другу и к другим культурам.

6. Организующая — визуальная опора позволяет использовать разные формы организации работы: индивидуальную, парную, групповую, а также проектную деятельность с учетом особенностей полилингвальной аудитории. 
Электронный научный журнал (Online). ISSN 2303-9922. http://www.vestospu.ru

Визуальная опора становится эффективным средством обучения говорению, если она проста и понятна, если материал изложен последовательно, логично и системно, если она воздействует эмоционально, вызывает реакцию, интерес, отклик и вовлекает учащегося в разговор.

Опираясь на тематику, можно выделить следующие типы визуальных опор:

- визуальные опоры портретного характера;

- визуальные опоры событийного характера.

Такие опоры будут побуждать к использованию разных способов изложения материала. В первом случае высказывание будет развертываться в пространственном плане, во втором - во временно́м. Например, визуальные опоры портретного характера «Я и моя семья», «Я и мое хобби», «Мой друг» позволят представить и описать себя и свою семью, рассказать о своих интересах и увлечениях. Визуальные опоры событийного характера «Мой учебный день», «Мои каникулы» предполагают рассказ, который будет разворачиваться во временно́м плане (утром, днем, вечером / сначала, потом, затем и т.д.).

По форме подачи материала визуальные опоры можно разделить на опоры, разработанные преподавателем, и опоры, подготовленные учащимися (рис. 1).

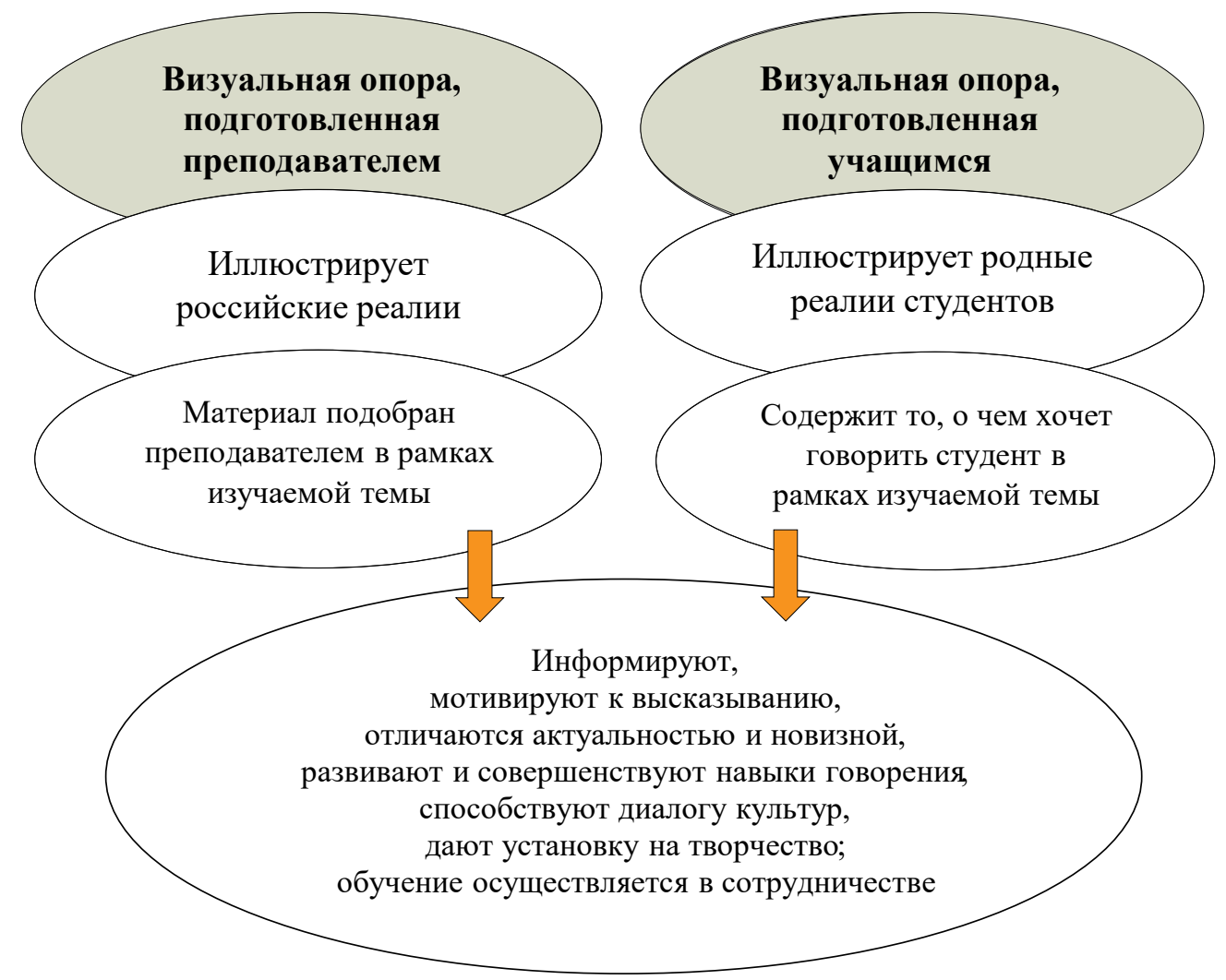

Рис. 1. Визуальные опоры на уроке русского языка как иностранного (содержание и функции)

Обучение осуществляется в сотрудничестве, студент активно вовлечен в работу. Готовя опору для высказывания по той или иной теме, он отбирает именно тот материал, о котором хочет рассказать. Таким образом, опора мотивирует к говорению. Она же мотивирует и к активному, вдумчивому слушанию, побуждает задать вопрос товарищу, поскольку речь идет о чем-то новом и интересном.

Приведем примеры заданий на говорение при работе с визуальной опорой в рамках темы «Интересы. Увлечения. Хобби». Визуальная опора в данном случае представляет 
Электронный научный журнал (Online). ISSN 2303-9922. http://www.vestospu.ru

собой фотоколлаж, где все фотоизображения «рассказывают» об увлечениях, интересах, привычках, хобби одного персонажа.

Задание 1. Опишите представленного персонажа. Внешность, возраст, интересы. Расскажите, что любит и что не любит представленный персонаж, чем он интересуется, что коллекционирует? Что мы узнаем о его привычках?

Методический комментарий: учащиеся продуцируют текст с элементами описания.

Задание 2. Сравните представленного персонажа и себя / своего брата / сестру, друга / подругу. Что вы любите так же, как и он? А что вы не любите, почему? Чем вы увлекаетесь и интересуетесь, почему? и т.д.

Методический комментарий: высказывание представляет собой сопоставительное описание, сравнительную характеристику с элементами рассуждения.

Задание 3. Подумайте, предположите, придумайте историю об этом персонаже (имя, фамилия, где живет, возраст, где учится, чем интересуется и почему, что коллекционировал в детстве, что коллекционирует сейчас и как ему пришла такая идея и т.д.).

Методический комментарий: тип продуцируемого текста-высказывания — контаминация (описание, рассуждение, повествование).

Таким образом, визуальная опора позволяет построить высказывания разного типа: описание, повествование, рассуждение, контаминацию.

Для создания разговорных ситуаций, развития и совершенствования навыков говорения нами разработаны и апробированы на начальном этапе обучения визуальные опоры, содержащие иллюстративный фотоматериал по темам «Семья», «Друг», «Портрет», «Хобби, увлечения, интересы», «Учеба в университете», «Учебная неделя. Расписание», «Выходной день», «Родной город», «Москва», «Погода. Времена года», «Еда» и др. Материалом для говорения также послужили визуальные опоры, созданные студентами.

Приведем фрагмент урока по теме «Родной город» с примером высказывания студентки Надежды С. из Черногории (родной язык сербохорватский) о городе Бар с опорой на фотоколлаж.

Я родилась в Баре в Черногории // Бар это небольшой город / прямо на берегу моря // на юге Черногории // это недалеко от Подгорищь / которая является столицей Черногории // в нём тринадиать тысяч жителей // он окружен горами / из которых главной является / гора Румия / на вершине которой находится иерковь // это мой район // мы жсили в квартире в центре города // когда мы были детьми / мы играли около дома // там были остатки старой иеркви / которая была разрушена во время одного землетрясения // в Баре есть что посмотреть и посетить // прежде всего у нас есть замок короля Николая // это летний дом короля Черногории // летом в этом городе полно туристов / и большинство из них русские // что мне нравится / в Черногории / это когда вы плаваете в море / у вас есть также вид на горы // рядом с пляжем есть также приятная прогулочная зона / с видом на море // существует также порт // и в циентре города вы можете увидеть много памятников // в непосредственной близости находится старый квартал // Бар это также старейший духовный центр // когда мне было семь лет / мы переехали в Подгорицу //

Работа в аудитории после «знакомства с городом Бар» организуется следующим образом: студентам предлагается 1) сказать, что они узнали о городе Бар, где он находится, что там можно увидеть и посетить; хотели бы они посетить Бар и почему; что интересного есть в Баре, чего нет в их родном городе; 2) задать Надежде интересующие их вопросы о городе.

Приведем примеры вопросов, заданных студентами: Как доехать до Бара из Страсбурга? Какие интересные сувениры можно привезти из Бара? Какие традици- 
Электронный научный журнал (Online). ISSN 2303-9922. http://www.vestospu.ru

онные блюда можно попробовать в местном ресторане? В какое кафе можно пойти? Какая погода в Баре летом? Какое море в Баре? В городе есть река? Почему в городе много туристов? Какие музеи есть в городе? В городе есть университет? Какие еще города есть в Черногории? Похож ли сербохорватский язык на русский? За что Надежда любит свой родной город?

На примере высказывания Надежды С. можно видеть, что визуальная опора не только помогла студентке построить монологическое высказывание о городе Бар и проиллюстрировать свой рассказ, но и явилась для слушателей источником новой социокультурной информации, что способствовало появлению вопросов и обсуждению сообщения. Другие студенты также рассказали о своем родном городе с последующим обсуждением и ответили на вопросы. Таким образом, в полилингвальной аудитории работа в рамках любой изучаемой темы является «выходом» в поликультурное пространство. Каждый студент представляет ту или иную культуру или культуры. Работа с визуальной опорой позволяет организовать на уроке обсуждение, что способствует обогащению языковых и культуроведческих знаний студентов, развитию и совершенствованию навыков говорения, формированию готовности к межкультурной коммуникации на русском языке.

На основе работы с фотоколлажем можно предложить студентам проектные задания: «10 причин, чтобы посетить...», «Экскурсия по родному городу», «10 самых интересных мест родного города» и др.

Анкетирование студентов, проведенное по окончании первого года обучения, показало, что работа с визуальной опорой на уроке по развитию навыков говорения помогает построить высказывание, лучше запомнить, понять и усвоить материал, стимулирует к спонтанному говорению. Иллюстрируя реалии, визуальная опора повышает мотивацию и эффективность обучения, информирует, снимает трудности понимания, развивает творческое воображение, индивидуализирует обучение (говорим о каждом и обо всех), позволяет вовлечь в разговор всех (что чрезвычайно важно при большой наполняемости групп в зарубежном вузе).

Таким образом, можно сделать следующие выводы:

1. Визуализация является важным условием реализации принципа наглядности, роль которого усиливается в связи с возрастающей потребностью повышения эффективности обучения, а также в связи с поиском новых методов обучения русскому языку как иностранному полилингвальной аудитории в условиях зарубежного вуза для формирования у учащихся лингвистической, коммуникативной и межкультурной компетенции.

2. Визуальная опора может быть разработана преподавателем и/или учащимися. Наш опыт показывает, что предложенный преподавателем образец оформления визуальной опоры мотивирует учащихся к поиску новых форм предъявления информации и творческому самовыражению.

3. Визуальная опора - средство обучения, обеспечивающее индивидуальную, парную и групповую работу студентов.

4. Визуальная опора может быть использована на разных этапах обучения: при знакомстве с новой лексикой, при построении простых и сложных предложений, при продуцировании монологического высказывания, а также для контроля.

5. Визуальная опора позволяет построить высказывания разного типа: описание, повествование, рассуждение, контаминацию.

6. В учебном процессе визуальная опора выполняет информативную, мотивирующую, обучающую, развивающую, воспитательную, организующую функции и тем самым является многофункциональным средством организации продуктивной речевой деятельности учащихся на занятиях по русскому языку как иностранному. 


\section{Электронный научный журнал (Online). ISSN 2303-9922. http://www.vestospu.ru}

\section{Список использованной литературы}

1. Абдрахманова И. Э. Дидактические возможности аудиовизуальных средств как ретрансляторов российской культуры на занятиях по русскому языку как иностранному // Вестник Тамбовского университета. Сер. Гуманитарные науки. 2009. № 7 (75). С. 207-211.

2. Абдулаев Э. Н. Использование визуальной информации в преподавании истории // Преподавание истории в школе. 2012. № 10. С. 7-11.

3. Азимов Э. Г., Щукин А. Н. Новый словарь методических терминов и понятий (теория и практика обучения языкам). М. : ИКАР, 2009. 448 с.

4. Вострикова Е. А. Организация коммуникации школьников в проектной деятельности визуальными средствами информационных технологий : дис. ... канд. пед. наук. Новокузнецк, 2004. 196 с.

5. Гадалина И. И., Исмаилова Х. Э. К вопросу создания учебных пособий по развитию речи с использованием ситуативных картинок // Вестник Московского государственного педагогического университета. Сер. Педагогика и психология. 2016. № 3 (37). С. 74-84.

6. Городилова Г. Г. Обучение речи и технические средства. М. : Русский язык, 1979. 206 с.

7. Дейкина А. Д., Янченко В. Д. Некоторые тенденции современной методики преподавания русского языка как иностранного // Современная коммуникативистика. 2018, № 1. С. 47-52.

8. Дистервег А. Избранные педагогические сочинения. М. : Учпедгиз, 1956. 378 с.

9. Заславская О. Ю., Пучкова Е. С. Анализ возможностей визуализации и подходы к ее применению для обучения информатике учителей начальных классов в системе среднего профессионального образования // Вестник Российского университета дружбы народов. Сер. Информатизация образования. 2015. № 3. C. $7-13$.

10. Заславская О. Ю., Пучкова Е. С. Визуализация и подходы к ее применению при обучении информатике учителей начальных классов в системе среднего профессионального образования // Вестник Московского городского педагогического университета. Сер. Информатика и информатизация образования. 2014. № 3 (29). С. $44-50$.

11. Зельманова Л. М. Наглядность в преподавании русского языка : пособие для учителя. М. : Просвещение, 1984. 159 с.

12. Коменский Я. А. Мир чувственных вещей в картинках // Избранные педагогические сочинения : в 2 т. М. : Педагогика, 1982. Т. 2. 576 с.

13. Ляховицкий М. В., Антипович Н. К., Бухбиндер В. А. [и др.]. Теория и практика применения технических средств в обучении иностранным языкам / под ред. М. В. Ляховицкого. Киев : Вища школа, 1979. $255 \mathrm{c}$.

14. Пассов Е. И. Основы коммуникативной методики обучения иноязычному общению. М. : Русский язык, 1989. 276 с.

15. Песталоцци И. Г. Как Гертруда учит своих детей // Избранные педагогические сочинения. М. : Педагогика, 1981. Т. 1. С. 61-212.

16. Рапуто А. Г. Визуализация как неотъемлемая составляющая процесса обучения преподавателей // Международный журнал экспериментального образования. 2010. № 5. С. 138-141.

17. Романова Н. Н., Амелина И. О., Черкашина Т. Т. Оптимизация работы с аутентичными аудиовидеоматериалами на занятиях по русскому языку как иностранному // Известия Юго-Западного государственного университета. Сер. Лингвистика и педагогика. 2018. Т. 8, № 2 (27). С. 83-92.

18. Сидельникова Т. Т. Потенциал и ограничения визуализации как метода изучения социально-гуманитарных дисциплин // Интеграция образования. 2016. Т. 20, № 2. С. 281-291.

19. Ушинский К. Д. Моя система воспитания. О нравственности / сост., предисл., коммент. В. О. Гусаковой. М. : АСТ, 2018. 572 с.

20. Щукин А. Н. Обучение речевому общению на русском языке как иностранном : учеб.-метод. пособие для преподавателей рус. языка как иностранного. 2-е изд., стер. М. : Русский язык. Курсы, 2015. 784 с.

21. Янченко В. Д. Принцип наглядности и его реализация в обучении русскому языку китайских студентов-филологов // Динамика языковых и культурных процессов в современной России : материалы V Конгресса РОПРЯЛ (г. Казань, 4-8 октября 2016 г.). СПб. : РОПРЯЛ, 2016. Вып. 5. С. 2174-2177.

22. Baptiste A., Belisle C., Pechenart J.-M. Le guide méthodologique. Des choix personnels aux compétences. Dossier Photo langage. Paris : Edition d'organisation, 1991. 214 p.

23. Muller C. La photographie, un outil pour communiquer en classe de langue // Recherche et pratiques pédagogiques en langues de spécialité — Cahiers de l’ APLIUT. 2012. Vol. XXXI, № 1. P. 10—27. URL: https:// journals.openedition.org/apliut/2224 (дата обращения 22.02.19). 


\title{
Электронный научный журнал (Online). ISSN 2303-9922. http://www.vestospu.ru
}

\author{
Антипова Наталья Борисовна, аспирант \\ Страсбургский университет \\ Французская республика, 67000, Страсбург, ул. Рене Декарта, 22 \\ E-mail: n.antipova@mail.ru
}

\section{UDC 372.881.161.1}

\section{N. B. Antipova}

\section{Didactic functions of visual support in the process of teaching Russian as a foreign language at the initial stage}

The article reveals the notions of visualization and visual support, considers the types of visual support used by the author at the initial stage of teaching Russian as a foreign language, describes the didactic functions of visual support as a multifunctional means of visualization, which contributes to the formation of correct ideas about the studied phenomena of language and culture, helps to perceive and generate speech. The author justifies the need to use visual supports when teaching speaking at the initial stage, describes her own experience of working with visual supports in the process of teaching Russian to a multilingual audience in a foreign university.

Key words: use of visual methods, visualization, visual aid, visual teaching environment, types of visual aids, functions of visual aid, polylingual group, teaching Russian as a foreign language, foreign students.

\author{
Antipova Natalia Borisovna, Postgraduate student \\ University of Strasburg \\ 22, Rene Descartes, Strasburg, 67000, French republic \\ E-mail: n.antipova@mail.ru
}

\section{References}

1. Abdrakhmanova I. E. Didakticheskie vozmozhnosti audiovizual'nykh sredstv kak retranslyatorov rossiiskoi kul'tury na zanyatiyakh po russkomu yazyku kak inostrannomu [The didactic possibilities of audiovisual means to transmit Russian culture at the lessons of Russian as a foreign language]. Vestnik Tambovskogo universiteta. Seriya: Gumanitarnye nauki - Tambov University Review. Series Humanities, 2009, no. 7 (75), pp. 207 -211. (In Russian)

2. Abdulaev E. N. Ispol'zovanie vizual'noi informatsii v prepodavanii istorii [Imaging techniques in the study of history]. Prepodavanie istorii $v$ shkole - The teaching of history in schools, 2012, no. 10, pp. 7-11. (In Russian)

3. Azimov E. G., Shchukin A. N. Novyi slovar' metodicheskikh terminov i ponyatii (teoriya $i$ praktika obucheniya yazykam) [New vocabulary of methodological terms and concepts (theory and practice of language teaching)]. Moscow, IKAR Publ., 2009. 448 p. (In Russian)

4. Vostrikova E. A. Organizatsiya kommunikatsii shkol'nikov v proektnoi deyatel'nosti vizual'nymi sredstvami informatsionnykh tekhnologii: dis. ... kand. ped. nauk [Arranging communication of schoolchildren in project activities by visual means of information technology. Cand. Dis.]. Novokuznetsk, 2004. 196 p. (In Russian)

5. Gadalina I. I., Ismailova Kh. E. K voprosu sozdaniya uchebnykh posobii po razvitiyu rechi s ispol'zovaniem situativnykh kartinok [On the issue of creating textbooks on speech development using situational pictures]. Vestnik Moskovskogo gosudarstvennogo pedagogicheskogo universiteta. Ser. Pedagogika i psikhologiya-Vestnik Moscow city university. Scientific Journal. Pedagogy and Psychology, 2016, no. 3 (37), pp. 74-84. (In Russian)

6. Gorodilova G. G. Obuchenie rechi $i$ tekhnicheskie sredstva [Speech training and technical facilities]. Moscow, Russkii yazyk Publ., 1979. 206 p. (In Russian)

7. Deikina A. D., Yanchenko V. D. Nekotorye tendentsii sovremennoi metodiki prepodavaniya russkogo yazyka kak inostrannogo [Some trends of modern methodology in teaching Russian as a foreign language]. Sovremennaya kommunikativistika — Scientific Research and Development. Modern Communication Studies, 2018, no. 1, pp. 47-52. (In Russian)

8. Disterveg A. Izbrannye pedagogicheskie sochineniya [Selected pedagogical works]. Moscow, Uchpedgiz Publ., 1956. 378 p. (In Russian) 


\section{Электронный научный журнал (Online). ISSN 2303-9922. http://www.vestospu.ru}

9. Zaslavskaya O. Yu., Puchkova E. S. Analiz vozmozhnostei vizualizatsii i podkhody k ee primeneniyu dlya obucheniya informatike uchitelei nachal'nykh klassov v sisteme srednego professional'nogo obrazovaniya [Analysis of opportunities of visualization and approaches to its application for training informatics of Primary school teachers in the system of secondary professional education]. Vestnik Rossiiskogo universiteta druzhby narodov. Ser. Informatizatsiya obrazovaniya - RUDN Journal of Informatization in Education, 2015, no. 3, pp. 7-13. (In Russian)

10. Zaslavskaya O. Yu., Puchkova E. S. Vizualizatsiya i podkhody k ee primeneniyu pri obuchenii informatike uchitelei nachal'nykh klassov v sisteme srednego professional'nogo obrazovaniya [Visualization and approaches to its use in teaching computer science teachers in the elementary school in the system of secondary professional education]. Vestnik Moskovskogo gorodskogo pedagogicheskogo universiteta. Ser. Informatika i informatizatsiya obrazovaniya - Vestnik Moscow city teacher training university. Scientific journal. Ser. "Informatics and informatization of education”, 2014, no. 3 (29), pp. 44-51. (In Russian)

11. Zel'manova L. M. Naglyadnost'v prepodavanii russkogo yazyka [Visibility in teaching of Russian]. Moscow, Prosveshchenie Publ., 1984. 159 p. (In Russian)

12. Komenskii Ya. A. Mir chuvstvennykh veshchei v kartinkakh [The world of sensual things in pictures]. Izbrannye pedagogicheskie sochineniya: $v 2 t$. [Selected pedagogical works. In 2 volumes]. Moscow, Pedagogika Publ., 1982, vol. 2, 576 p. (In Russian)

13. Lyakhovitskii M. V., Antipovich N. K., Bukhbinder V. A. [et al.]. Teoriya i praktika primeneniya tekhnicheskikh sredstv $v$ obuchenii inostrannym yazykam [Theory and practice of using technical means in teaching foreign languages]. Kiev, Vishcha shkola Publ., 1979. 255 p. (In Russian)

14. Passov E. I. Osnovy kommunikativnoi metodiki obucheniya inoyazychnomu obshcheniyu [Fundamentals of communicative method of teaching foreign language communication]. Moscow, Russkii yazyk Publ., 1989. 276 p. (In Russian)

15. Pestalotstsi I. G. Kak Gertruda uchit svoikh detei [How Gertrude Teaches Her Children]. Izbrannye pedagogicheskie sochineniya [Selected pedagogical works]. Moscow, Pedagogika Publ., 1981, vol. 1, pp. 61— 212. (In Russian)

16. Raputo A. G. Vizualizatsiya kak neot"emlemaya sostavlyayushchaya protsessa obucheniya prepodavatelei [Visualization as an integral part of the training process for teachers]. Mezhdunarodnyi zhurnal eksperimental'nogo obrazovaniya, 2010, no. 5, pp. 138-141. (In Russian)

17. Romanova N. N., Amelina I. O., Cherkashina T. T. Optimizatsiya raboty s autentichnymi audiovideomaterialami na zanyatiyakh po russkomu yazyku kak inostrannomu [Optimization of work with authentic audiovideomaterials at the lessons of Russian as a foreign language]. Izvestiya Yugo-Zapadnogo gosudarstvennogo universiteta. Ser. Lingvistika i pedagogika - Proceedings of the Southwest State University. Ser. "Linguistics and Pedagogics", 2018, vol. 8, no. 2 (27), pp. 83-92. (In Russian)

18. Sidel'nikova T. T. Potentsial i ogranicheniya vizualizatsii kak metoda izucheniya sotsial'no-gumanitarnykh distsiplin [The potential and limitations of visualisation as a method in learning social sciences and humanities]. Integratsiya obrazovaniya - Integration of education, 2016, vol. 20, no. 2, P. 281-291. DOI: 10.15507/19919468.083.020.201602.281-292 (In Russian)

19. Ushinskii K. D. Moya sistema vospitaniya. O nravstvennosti [My parenting system. On the issue of morality]. Moscow, AST Publ., 2018. 572 p. (In Russian)

20. Shchukin A. N. Obuchenie rechevomu obshcheniyu na russkom yazyke kak inostrannom [Teaching speech communication in Russian as a foreign language]. Moscow, Russkii yazyk. Kursy Publ., 2015. 784 p. (In Russian)

21. Yanchenko V. D. Printsip naglyadnosti i ego realizatsiya v obuchenii russkomu yazyku kitaiskikh studentov-filologov [The principle of visualization and its implementation in teaching Russian to Chinese philology students]. Dinamika yazykovykh i kul 'turnykh protsessov v sovremennoi Rossii: materialy V Kongressa ROPRYaL (g. Kazan', 4-8 oktyabrya 2016 g.) [Dynamics of linguistic and cultural processes in modern Russia. Proceedings of the $5^{\text {th }}$ ROPRYaL Congress (Kazan, October 4-8, 2016)]. St. Petersburg, ROPRYaL Publ., 2016, is. 5, pp. 2174-2177. (In Russian)

22. Baptiste A., Belisle C., Pechenart J.-M. Le guide méthodologique. Des choix personnels aux compétences. Dossier Photo langage. Paris, Edition d'organisation, 1991. 214 p.

23. Muller C. La photographie, un outil pour communiquer en classe de langue. Recherche et pratiques pédagogiques en langues de spécialité - Cahiers de l' APLIUT, 2012, vol. XXXI, no. 1, pp. 10_27. Available at: https://journals.openedition.org/apliut/2224. Accessed 22.02.19. 